\title{
The Prognostic Value of Circulatory Cancer Cells after Debulking of Advanced Ovarian Tumor
}

\author{
Attia Mohamed
}

Department of Obstetrics and Gynecology, Faculty of Medicine, Al-Azhar University, Cairo, Egypt

Corresponding author: Attia Mohamed, Email: elbalkinyattia@gmail.com

\begin{abstract}
Background: There is a recent focus on circulatory cancer cells (CCCs) as a prognostic biomarker for many malignant cancers. We aimed to investigate the association between the presence of CCCs before the surgery in patients with advanced ovarian cancer (AOC) and the survival of these patients. Methods: We included in this study 30 women with AOC and eligible for debulking. Blood samples were obtained before and after the surgery and the CCCs were counted using the optimized tapered-slit filter technique. The association between these cells and the survival of these patient was analyzed.

Results: The median age of the included women was 57 years, while the median follow-up period was 29.3 months. There was no difference between the counts of CCCs before and after the debulking $(\mathrm{P}>0.05)$. There was no association between the post-debulking CCCs and the 3-year progression-free survival (PFS) (P>0.05) or the overall survival (OS) $(\mathrm{P}>0.05)$. There was an association between frequent presence of lymph node involvement and the presence of post-debulking CCCs $(\mathrm{P}<0.01)$. However not significant, there was an association between the post-debulking CCCs and the PFS in women with very advanced cancers $(\mathrm{P}>0.05)$.

Conclusion: The presence of post-debulking CCCs was proven to be associated with bad prognosis as it showed to be associated with poor PFS. Further studies are required to enforce these findings.
\end{abstract}

Keywords: Ovarian cancer; Circulatory cancer cells; Prognosis.

\section{INTRODUCTION}

As compared with other gynecological malignancies, ovarian tumor was proven to be the most gynecological tumor associated with poor prognosis ${ }^{(1)}$. Due to the lack of presence of early biomarkers or presence of clinical symptoms, ovarian cancer mostly reaches the advanced stages. Around $80 \%$ of patients with ovarian cancer relapse after the debulking and the chemotherapy ${ }^{(2)}$. The follow-up of such patient is conducted via both cancer antigen-125 (CA-125) and CT scan; however, its sensitivity in diagnosis of recurrence do not exceed $70 \%{ }^{(3,4)}$. This is due to the inappropriate immune response associated with recurrence due to the small amount of antigen secreted from the small recurrent tumor cells. Therefore, these biomarkers are not welleffective in diagnosis of cancer recurrence after the surgery in patients with ovarian cancer, and the search for effective biomarker is an urgent need.

There is a recent focus on circulatory cancer cells (CCCs) as a prognostic biomarker for many malignant cancers including the ovarian cancer. They are individual malignant cells or nests that originate from the main cancer and enter the blood through the vascular invasion and they could reach the distant cells to form metastasis ${ }^{5-}$ ${ }^{7}$. Occurrence of metastasis is the most critical outcome that survivors fear from; therefore, catching these cells in the blood and the early prediction of metastasis has gain the attention of many researchers. There are many studies that were performed on breast colorectal, and prostatic cancers and revealed that the CCCs is associated with bad prognosis; as they were reported to be associated with shorter progression-free survival (PFS) and overall survival (OS) in these cancers. However, there were a contradiction regarding these cells whether associated or not with bad prognosis of ovarian cancer ${ }^{8-14}$.

Therefore, if CCCs could predict the tumor activity or metastasis occurrence, we could develop more optimal treatment options to enhance the survival of patients with ovarian cancer. Therefore, we aimed to investigate the association between the presence of CCCs before the surgery in patients with advanced ovarian cancer (AOC) and the survival of these patients.

\section{Methods}

Throughout the inclusion period, we included 30 women with ovarian cancer and eligible for staging operation who were admitted in Bab-Elshaarya University Hospital, Cairo, Egypt. The recruitment period was conducted throughout the entire year of 2018. Patients with any malignant tumor in the last 5 years were excluded from the study.

\section{Ethical approval:}

A written informed consent was obtained from each participant and the institutional review board of AlAzhar university approved the study. This study was conducted under the declaration of Helsinki. 
Before the surgery by one month, the level of CA-125, risk of malignancy index (RMI), and risk of ovarian malignancy algorithm (ROMA) were assessed ${ }^{15}$. CT scan or MRI scan were used to assess the degree of ascites which graded as either grade 2, moderate ascites with symmetrical abdominal distension, or grade 3, severe ascites with marked abdominal distension ${ }^{16}$.

Among the included patients, 10 patients were considered to be have disseminated tumor before the surgery as indicated by the cytology of the ascites or the biopsy from the ovary; therefore, they received neoadjuvant chemotherapy before the operation. They were not suitable for the debulking operation as the tumor was either unresectable or with bad performance. After the operation, the histopathology was conducted for all patients to confirm the diagnosis, tumor grade, and stage. After the operation by one week, the residual was assessed to type the operation as optimal, if it was less than $1 \mathrm{~cm}$, or suboptimal, if the residual was more than that.

\section{Blood collection and CCCs identification}

Before the operation, $5 \mathrm{ml}$ of blood was collected from each patient in a heparinized tube for CCCs. Similarly, identical amount was obtained after the operation by one month before starting the neoadjuvant chemotherapy.

Tapered-slit filter (TSF) technique was used to isolate the CCCs as previously reported ${ }^{17}$. The physical features of the cells are the determinant criteria that the isolation is based on according to the TSF which has not any association with the protein expressed on the surface of the cells. Due to the wideness of the entrance and the vice versa of the exit, the sample flow is optimized and the cellular stress is decreased. We used the immune staining that was mentioned in previous report in the $\mathrm{TSF}^{18}$. The MetaMorph software was used for cell quantification after the immunofluorescence staining. The cells were counted based on both staining and morphological criteria.

\section{Statistical analysis}

The statistical analysis was performed using the SPSS software version 23 . The quantitative data were expressed median and range. The qualitative data were expressed as frequency and percentage. The survival rates were assessed using the Kaplan-Meier analysis. The categorical variables were compared using either Fisher's exact test or chi-square test. The degree of significance was set when the $\mathrm{P}<0.05$.

\section{RESULTS}

The demographic characteristics of the patients are in table 1 . There was a significant difference as regard the CCCs counts between pre- and post-operation $(76.7 \%$ vs $50 \%, \mathrm{P}<0.05)$.
Around $76.6 \%$ of the patients underwent total staging operation. Fertility-preserving operation was conducted for five women with their cancer present in one ovary and they were premenopausal. Palliative debulking without lymphadenectomy was conducted for two patients due to distal metastasis. Ideal debulking surgery was conducted for $25(83.3 \%)$ women.

Advanced FIGO stage III-IV was found in 21 patients after the operation. Adjuvant chemotherapy was conducted for 13 women after the surgery. Among the included patients, 14 showed recurrence, two were resistant for the chemotherapy. Mortality occurred in two patients throughout the study period (Table 1).

Table 1. The demographic characteristics of the patients $(\mathrm{n}=30)$

\begin{tabular}{|l|l|}
\hline Variable & $\begin{array}{l}\text { Value (number and } \\
\text { percentages \% or } \\
\text { median and range }\end{array}$ \\
\hline Age at diagnosis (years) & $57(22-79)$ \\
\hline $\begin{array}{l}\text { Preoperative serum CA-125 } \\
\text { (U/ml) }\end{array}$ & $185.4(7.3-3798.4)$ \\
\hline Preoperative ROMA ${ }^{*}(\%)$ & $49.8(4.2-98.9)$ \\
\hline $\begin{array}{l}\text { Preoperative serum CCCs } \\
\text { detection }\end{array}$ & $23(76.7)$ \\
\hline Moderate to severe ascites & $13(43.3)$ \\
\hline Neoadjuvant chemotherapy & $13(43.3)$ \\
\hline Complete surgical staging & $23(76.6)$ \\
\hline FIGO stage & $5(16.7)$ \\
\hline I & $4(13.3)$ \\
\hline II & $11(36.7)$ \\
\hline III & $10(33.3)$ \\
\hline IV & \\
\hline Histologic type & $16(53.3)$ \\
\hline Serous & $3(10)$ \\
\hline Endometrioid & $2(6.7)$ \\
\hline Clear cell & $4(13.3)$ \\
\hline Mucinous & $5(16.7)$ \\
\hline Others & $4(13.3)$ \\
\hline Tumor grade & $23(76.6)$ \\
\hline 1 & $8.9(0.6-25.4)$ \\
\hline $2-3$ & $25(83.3)$ \\
\hline Tumor size (cm) & $15(50)$ \\
\hline $\begin{array}{l}\text { Presence of Residual tumor } \\
\text { 1 cm }\end{array}$ & $14(46.7)$ \\
\hline $\begin{array}{l}\text { Postoperative presence of } \\
\text { CCCs }\end{array}$ & $2(6.7)$ \\
\hline Recurrence & \\
\hline Death & \\
\hline & \\
\hline
\end{tabular}

CA-125 $=$ cancer antigen 125 , FIGO $=$ The International Federation of Gynecology and Obstetrics, ROMA = risk of ovarian malignancy algorithm. 


\section{Relations of CCCs with the tumor characteristics}

There was no association between the CCCs and the clinical or pathologic tumor characteristics either preoperative or postoperative except for the FIGO calssification. Furthermore, there was no association between the presence of CCCs neither preoperative nor postoperative and the ideal debulking surgery. Moreover, the mortality and morbidity were shown to be not associated with presence of CCCs neither preoperative nor postoperative (Tables 2 and 3 ).

Table 2. Relationship between the preoperative circulating tumor cells and the patients' characteristics $(n=30)$

\begin{tabular}{|c|c|c|c|c|}
\hline Variable & number & Negative CCCs & Positive CCCs & $\mathrm{P}$ value \\
\hline Age at diagnosis (years) & & & & \multirow[t]{3}{*}{$>0.05$} \\
\hline$<57$ & 15 & $3(42.9)$ & $12(52.2)$ & \\
\hline$>57$ & 15 & $4(57.1)$ & $11(47.8)$ & \\
\hline Preoperative CA-125 (U/ml) & & & & \multirow[t]{3}{*}{$>0.05$} \\
\hline Negative & 9 & $3(42.9)$ & $6(26.1)$ & \\
\hline Positive & 21 & $4(57.1)$ & $17(73.9)$ & \\
\hline Moderate to severe ascites & & & & \multirow[t]{3}{*}{$>0.05$} \\
\hline Negative & 17 & $6(66.7)$ & $11(52.2)$ & \\
\hline Positive & 13 & $3(33.3)$ & $10(47.8)$ & \\
\hline Neoadjuvant chemotherapy & & & & \multirow[t]{3}{*}{$>0.05$} \\
\hline No & 17 & $7(70 \%)$ & $10(50)$ & \\
\hline Yes & 13 & $3(30)$ & $10(50)$ & \\
\hline FIGO stage & & & & \multirow{3}{*}{$<0.05$} \\
\hline I-II & 9 & 0 & $9(42.8)$ & \\
\hline III-IV & 21 & $9(100)$ & $12(57.2)$ & \\
\hline Histologic type & & & & \multirow[t]{3}{*}{$>0.05$} \\
\hline Serous & 16 & $5(71.4)$ & $11(47.8)$ & \\
\hline Nonserous & 14 & $2(28.6)$ & $12(52.2)$ & \\
\hline Tumor grade & & & & \multirow[t]{3}{*}{$>0.05$} \\
\hline 1 & 4 & $1(14.3)$ & $3(15.0)$ & \\
\hline $2-3$ & 23 & $6(85.7)$ & $17(85.0)$ & \\
\hline Residual tumor $>1.0 \mathrm{~cm}$ & & & & \multirow[t]{3}{*}{$>0.05$} \\
\hline No & 5 & $2(28.6)$ & $3(13.0)$ & \\
\hline Yes & 25 & $5(71.4)$ & $20(87.0)$ & \\
\hline Recurrence & & & & \multirow[t]{3}{*}{$>0.05$} \\
\hline No & 16 & $3(37.5)$ & $13(59.1)$ & \\
\hline Yes & 14 & $5(62.5)$ & $9(40.9)$ & \\
\hline Death & & & & \multirow[t]{3}{*}{$>0.05$} \\
\hline No & 28 & $7(100)$ & $21(91.3)$ & \\
\hline Yes & 2 & 0 & $2(8.7)$ & \\
\hline
\end{tabular}


Table 3. Relationship between the postoperative circulating tumor cells and the patients' characteristics $(\mathrm{n}=28)$

\begin{tabular}{|c|c|c|c|c|}
\hline Variable & number & Negative CCCs & Positive CCCs & $\mathrm{P}$ value \\
\hline Age at diagnosis (years) & & & & \multirow[t]{3}{*}{$>0.05$} \\
\hline$<57$ & 14 & $3(42.9)$ & $11(52.4)$ & \\
\hline$>57$ & 14 & $4(57.1)$ & $10(47.6)$ & \\
\hline Preoperative CA-125 (U/ml) & & & & \multirow[t]{3}{*}{$>0.05$} \\
\hline Negative & 10 & $3(50)$ & $6(27.3)$ & \\
\hline Positive & 18 & $3(50)$ & $16(72.7)$ & \\
\hline Moderate to severe ascites & & & & \multirow[t]{3}{*}{$>0.05$} \\
\hline Negative & 15 & $5(62.5)$ & $10(50)$ & \\
\hline Positive & 13 & $3(37.5)$ & $10(50)$ & \\
\hline Neoadjuvant chemotherapy & & & & \multirow[t]{3}{*}{$>0.05$} \\
\hline No & 17 & $7(75)$ & $10(52.6)$ & \\
\hline Yes & 11 & $2(25)$ & $9(47.4)$ & \\
\hline FIGO stage & & & & \multirow[t]{3}{*}{$>0.05$} \\
\hline I-II & 8 & 0 & $8(40)$ & \\
\hline III-IV & 20 & $8(100)$ & $12(60)$ & \\
\hline Histologic type & & & & \multirow[t]{3}{*}{$>0.05$} \\
\hline Serous & 15 & $4(66.7)$ & $11(50)$ & \\
\hline Nonserous & 13 & $2(33.3)$ & $11(50)$ & \\
\hline Tumor grade & & & & \multirow[t]{3}{*}{$>0.05$} \\
\hline 1 & 4 & $1(16.7)$ & $3(15.0)$ & \\
\hline $2-3$ & 22 & $5(83.3)$ & $17(85.0)$ & \\
\hline Residual tumor $>1.0 \mathrm{~cm}$ & & & & \multirow[t]{3}{*}{$>0.05$} \\
\hline No & 4 & $2(33.3)$ & $2(13.0)$ & \\
\hline Yes & 24 & $4(66.7)$ & $20(87.0)$ & \\
\hline Recurrence & & & & \multirow[t]{3}{*}{$>0.05$} \\
\hline No & 15 & $2(37.5)$ & $13(59.1)$ & \\
\hline Yes & 13 & $5(62.5)$ & $8(40.9)$ & \\
\hline Death & & & & \multirow[t]{3}{*}{$>0.05$} \\
\hline No & 26 & $6(100)$ & $20(90.9)$ & \\
\hline Yes & 2 & 0 & $2(9.1)$ & \\
\hline
\end{tabular}

CA-125 = cancer antigen 125, FIGO = The International Federation of Gynecology and Obstetrics.

Having the patients with advanced tumor, presence of CCCs postoperatively was shown to be associated with presence of affected lymph nodes as there were seven patients with positive lymph nodes, and all of them were positive for postoperative CCCs, while only three among them were revealed to have CCCs. There was no association between the presence of CCCs and presence of metastasis; however the residual tumor more than $1 \mathrm{~cm}$ was shown to be associated with presence of CCCs (Table 4). 


\begin{tabular}{|c|c|c|c|c|}
\hline Variable & number & Negative CCCs & Positive CCCs & $\mathrm{P}$ value \\
\hline Age at diagnosis (years) & & & & $>0.05$ \\
\hline$<57$ & 10 & $3(60)$ & $7(53.8)$ & \\
\hline$>57$ & 8 & $2(40)$ & $6(46.2)$ & \\
\hline Preoperative CA-125 (U/ml) & & & & $>0.05$ \\
\hline Negative & 6 & $2(40)$ & $4(30.8)$ & \\
\hline Positive & 12 & $3(60)$ & $9(69.2)$ & \\
\hline Moderate to severe ascites & & & & $>0.05$ \\
\hline Negative & 8 & $3(50)$ & $5(41.7)$ & \\
\hline Positive & 10 & $3(50)$ & $7(58.3)$ & \\
\hline Neoadjuvant chemotherapy & & & & $>0.05$ \\
\hline No & 8 & $2(50)$ & $6(42.8)$ & \\
\hline Yes & 10 & $2(50)$ & $8(57.2)$ & \\
\hline Lymph node involvement & & & & $<0.01$ \\
\hline No & 10 & $7(100)$ & $3(30.0)$ & \\
\hline Yes & 7 & 0 & $7(70.0)$ & \\
\hline Omentum involvement & & & & $>0.05$ \\
\hline No & 9 & $4(57.1)$ & $5(45.5)$ & \\
\hline Yes & 9 & $3(42.9)$ & $6(54.5)$ & \\
\hline Distant metastasis & & & & $>0.05$ \\
\hline No & 9 & $2(28.6)$ & $7(58.3)$ & \\
\hline Yes & 10 & $5(71.4)$ & $5(41.7)$ & \\
\hline Histologic type & & & & 0.991 \\
\hline Serous & 12 & $4(66.7)$ & $8(66.7)$ & \\
\hline Nonserous & 6 & $2(33.3)$ & $4(33.3)$ & \\
\hline Tumor grade & & & & $>0.05$ \\
\hline 1 & 1 & 0 & $1(7.7)$ & \\
\hline $2-3$ & 17 & $5(100)$ & $12(92.3)$ & \\
\hline Residual tumor $>1.0 \mathrm{~cm}$ & & & & $<0.05$ \\
\hline No & 3 & $3(42.8)$ & 0 & \\
\hline Yes & 15 & $4(57.2)$ & $11(100)$ & \\
\hline Recurrence & & & & $>0.05$ \\
\hline No & 8 & $2(40)$ & $6(46.2)$ & \\
\hline Yes & 10 & $3(60)$ & $7(53.8)$ & \\
\hline Death & & & & $>0.05$ \\
\hline No & 18 & $6(100)$ & $12(100)$ & \\
\hline Yes & 0 & 0 & 0 & \\
\hline
\end{tabular}

Values are presented as number (\%).

\section{Association between CCCs and survival}

Having the three-year progression-free-survival, there was no difference between patients with preoperative $\mathrm{CCCs}$ and patients without preoperative CCCs $(\mathrm{P}>0.05)$. Similarly, there was no association between the two groups regarding the overall survival ( $\mathrm{P}>0.05)$. Having the postoperative CCCs, there was no significant association with neither progression-free survival $(\mathrm{P}>0.05)$ nor the overall survival $(\mathrm{P}>0.05)$
(Figure 1). The subgroup analysis showed that patients with advanced stages of the diseases and with postoperative CCCs were associated with relatively lower progression-free survival rates than patients with advanced stages but without CCCs; however, not statistically significant $(\mathrm{P}>0.05)$. However, there was no difference between patients with advanced stages and preoperative $\mathrm{CCCs}$ and patients with advanced stages but without preoperative CCCs ( $>$ >0.05) (Figure 2). 

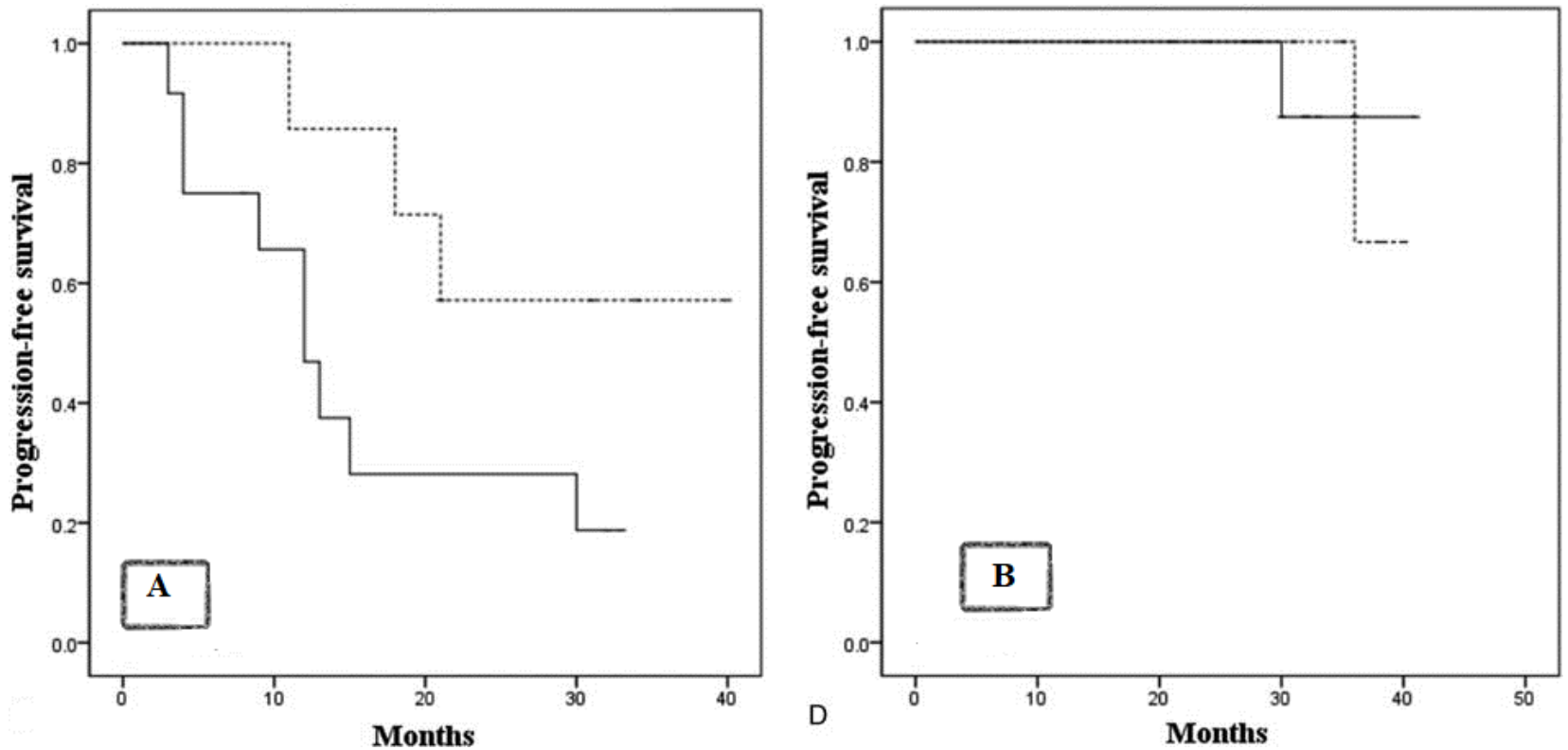

Figure 1. Kaplan-Meier curves comparing the survival between patients with postoperative negative versus positive circulating cancer cells (CCCs). A) The Progression-free survival; B) Overall survival. Continuous line: CCCs positive. Interrupted line: CCCs negative.
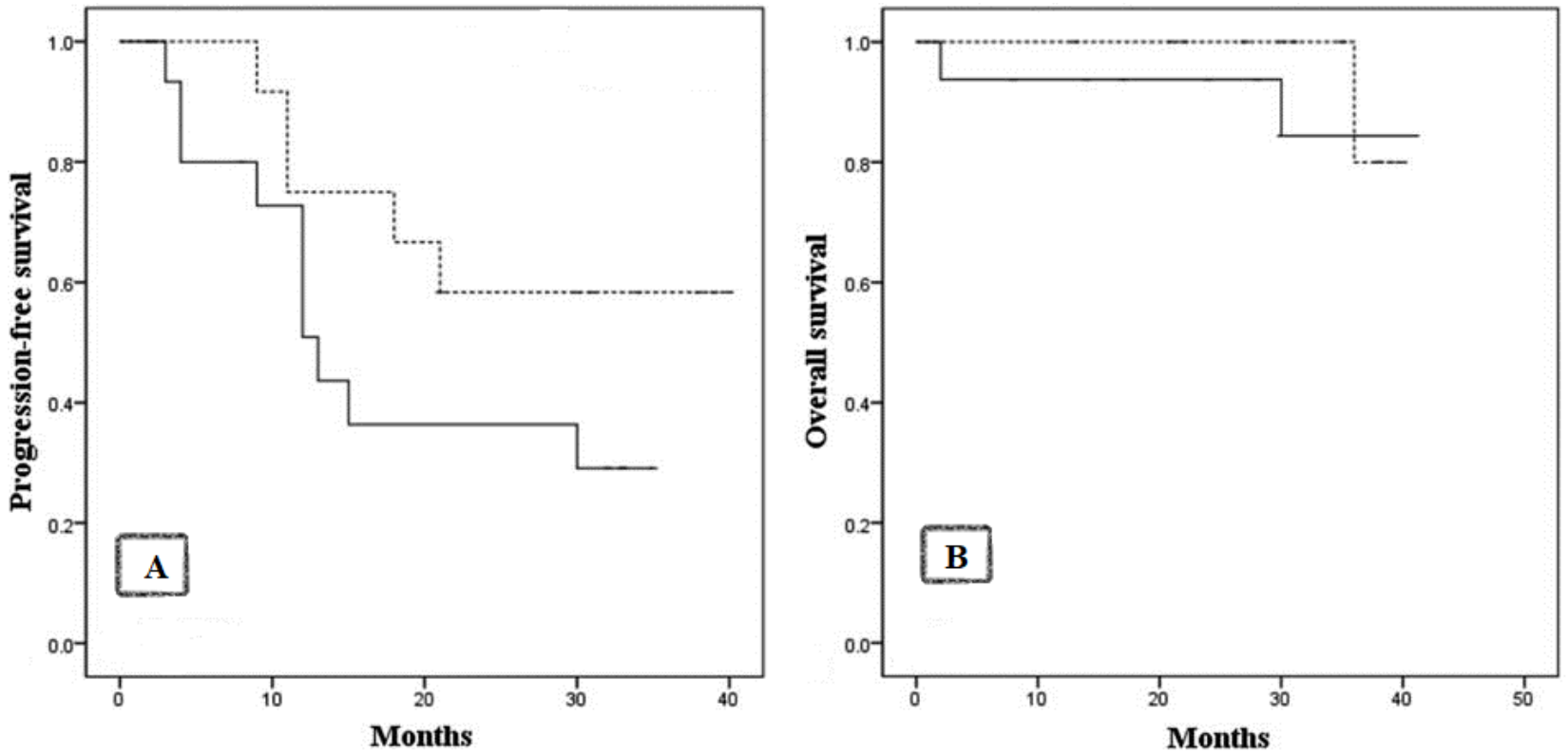

Figure 2. Kaplan-Meier curves comparing the survival between patients with advanced stages of the disease and with either postoperative negative or positive circulating cancer cells (CCCs). A) The progression-free survival; B) Overall survival. Continuous line: CCCs positive. Interrupted line: CCCs negative.

\section{DISCUSSION}

In this study, we isolated CCCs from peripheral blood of patients with ovarian tumor and we revealed that the presence of CCCs in peripheral blood preoperative was not associated with the tumor characteristics or grading. Furthermore, there was no association between the CCCs and the tumor stage or its optimal removal. However, there was a tendency of association between presence of CCCs postoperatively and progression-free survival in patient with advanced stages of the disease. Furthermore, there was association between lymph node involvement and presence of CCCs postoperatively.

With the beginning of the $21^{\text {th }}$ century, there was a belief that the spread of the ovarian tumor occurs primarily through the creeping of cells through the peritoneal cavity; therefore, the identification of CCCs in the peripheral blood did not make sense ${ }^{13}$. However, many recent studies hypothesized the association between the survival of patients with ovarian tumor and the presence of CCCs in the peripheral blood ${ }^{8-10}$. In agreement with our study, Obermayr and his colleague revealed positive association between 
presence of CCCs and the survival rates postoperatively but not at the first diagnosis with the disease ${ }^{10}$. This will help in knowing the actual state and the behavior of the disease especially after the surgery and the postoperative chemotherapy, which in turn will help in knowing the optimal plan of management. Furthermore, Fan and his team revealed positive association between presence of CCCs and the increased level of CA-125 and the advanced stages of the tumor ${ }^{9}$. Obermayr et al., suggested that the presence of CCCs postoperatively may be an indication of suboptimal debulking and failure of the chemotherapy ${ }^{10}$. However, our study did not show this association between the CCCs and the optimal debulking, the stage of the tumor, the level of CA-125, or chemotherapy usage. This may be due to the small sample size in our study; however, the association of CCCs in peripheral blood with lymph node involvement in advanced tumor can be explained by the possible spread of cancer cells during the intraoperative manipulation of the affected lymph nodes. The possible cause of insignificant difference between pre and post-surgery regarding the level of CCCs is that the CCCs spread before the surgery into the blood in advanced stage, and the extra liberated cells after the surgery could not be enough to induce a significant difference. This can explain the increase of CCCs in metastatic lymph nodes which is due to ruptured of metastatic lymph node or lymphatic break ${ }^{19}$. Our results were against the results revealed by previous studies that shown that there was no association between the lymph node involvement and the presence of CCCs in the circulating blood $^{10}$; however, this association was proven in other cancers including colorectal and breast cancer $^{20}$.

In conclusion, the results of this study highlighted the potential value of CCCs in the prognosis of patient with advanced ovarian tumor; however, further large-sample studies are needed to validate these results. Detection of CCCs may provide information regarding the state of the surgery and the success of the chemotherapy. Furthermore, it may guide us for other additional therapeutic plans.

\section{REFERENCES}

1. Baldwin L, Huang B, Miller $R$ et al. (2012):Ten-year relative survival for epithelial ovarian cancer. Obstet Gynecol .,120:612-8.

2. Yap T, Carden C, Kaye S (2009): Beyond chemotherapy: targeted therapies in ovarian cancer. Nat Rev Cancer ,9:16781 .

3. Yang Z, Zhao B, Li L (2016): The significance of the change pattern of serum CA125 level for judging prognosis and diagnosing recurrences of epithelial ovarian cancer. J Ovarian Res .,9:57.

4. Guo N, Peng Z (2017): Does serum CA125 have clinical value for follow-up monitoring of postoperative patients with epithelial ovarian cancer? Results of a 12-year study. J Ovarian Res. ,10:14.

5. Schwarzenbach H, Hoon D, Pantel K (2011): Cell-free nucleic acids as biomarkers in cancer patients. Nat Rev
Cancer,11:426-37.

6. Masuda T, Hayashi N, Iguchi T (2016): Clinical and biological significance of circulating tumor cells in cancer. Mol Oncol., 10:408-17.

7. Bettegowda C, Sausen M, Leary R (2014): Detection of circulating tumor DNA in early- and late-stage human malignancies. Sci Transl Med. ,6:224.

8. Poveda A, Kaye S, McCormack R (2011): Circulating tumor cells predict progression free survival and overall survival in patients with relapsed/ recurrent advanced ovarian cancer. Gynecol Oncol .,122:567-72.

9. Fan T, Zhao Q, Chen J (2009): Clinical significance of circulating tumor cells detected by an invasion assay in peripheral blood of patients with ovarian cancer. Gynecol Oncol. ,112:185-91.

10. Obermayr E, Castillo-Tong D, Pils D (2013): Molecular characterization of circulating tumor cells in patients with ovarian cancer improves their prognostic significance - A study of the OVCAD consortium. Gynecol Oncol. ,128:1521.

11. Zeng L, Liang X, Liu Q (2017): The predictive value of circulating tumor cells in ovarian cancer a meta analysis. Int J Gynecol Cancer ,27:1109-17.

12. Cui L, Kwong J, Wang C (2015): Prognostic value of circulating tumor cells and disseminated tumor cells in patients with ovarian cancer: a systematic review and meta-analysis. J Ovarian Res. , 8:38.

13. Judson $P$, Geller M, Bliss $R$ et al. (2003): Preoperative detection of peripherally circulating cancer cells and its prognostic significance in ovarian cancer. Gynecol Oncol .,91:389-94.

14. Behbakht K, Sill M, Darcy K et al. (2011): Phase II trial of the mTOR inhibitor, temsirolimus and evaluation of circulating tumor cells and tumor biomarkers in persistent and recurrent epithelial ovarian and primary peritoneal malignancies: a Gynecologic Oncology Group study. Gynecol Oncol .,123:19-26.

15. Karlsen M, Sandhu N, Høgdall C et al. (2012): Evaluation of HE4, CA125, risk of ovarian malignancy algorithm (ROMA) and risk of malignancy index (RMI) as diagnostic tools of epithelial ovarian cancer in patients with a pelvic mass. Gynecol Oncol .,127:379-83.

16. Moore K, Aithal G (2006): Guidelines on the management of ascites in cirrhosis. Gut ,55(6):vi1-2.

17. Kang Y, Doh I, Cho Y (2015): Tapered-slit membrane filters for high- throughput viable circulating tumor cell isolation. Biomed Microdevices , 17:45.

18. Seo H, Hwang Y, Choe K et al. (2015): In vivo quantitation of injected circulating tumor cells from great saphenous vein based on video-rate confocal microscopy. Biomed Opt Express ,6:2158-67.

19. Camara O, Kavallaris A, Nöschel H et al. (2006): Seeding of epithelial cells into circulation during surgery for breast cancer: the fate of malignant and benign mobilized cells. World J Surg Oncol .,4:67.

20. Janni W, Rack B, Terstappen L et al. (2016): Pooled analysis of the prognostic relevance of circulating tumor cells in primary breast cancer. Clin Cancer Res .,22:2583-3593. 